Dian Arymami: Diskoneksi Nomad: Paradoks Kemenjadian dalam Sosial Media bertema Travelling

\title{
Diskoneksi Nomad: Paradoks Kemenjadian dalam Sosial Media bertema Travelling
}

\author{
Dian Arymami \\ Departemen Ilmu Komunikasi, Universitas Gadjah Mada \\ Bulaksumur, Caturtunggal, Kec. Depok, Kabupaten Sleman, Daerah Istimewa Yogyakarta 55281 \\ arymami@ugm.ac.id
}

Masuk tanggal : 06-11-2018, revisi tanggal : 07-03-2019, diterima untuk diterbitkan tanggal : 13-09-2019

\begin{abstract}
In the midst of global economic development, traveling activities have experienced a rapid increase as a culture of leisure and recreation among the people of Indonesia. The journey narrated by bloggers and influencers (influencers) has created its own lifestyle trends and further values that are intertwined with the daily culture of society. This study examines the narrative of the journey of bloggers on Instagram as textual artifacts to gain insight into how the values and culture of human life are woven into the phenomenon of travel. This study uses semiotic analysis which is read further by using the Deleuze and Guattari concepts regarding the 'becoming self'. This research departs from narrative assumptions and representations which are seen as representative of molecular political forms that subvert the molar identity and fixed position. The results of this research show representations of travel extending the value of independence, solitude, individualism, creativity, freedom and modernity. Where the journey itself is seen as a primary need that is pleasant, cheerful and calming. Furthermore, in the eyes of schizophrenic unconsciousness, the phenomenon of traveling mediated by the text of bloggers confirms the presence of schizo subjects. A paradoxical subject, where the collective movement through travel is a joint movement to be alone.
\end{abstract}

Keywords: Deleuze-Guattari, information society, social media, travelling, travelling blogs

\begin{abstract}
Abstrak
Di tengah perkembangan ekonomi global, aktifitas travelling mengalami peningkatan pesat sebagai budaya kesenangan di waktu luang (leisure) dan rekreasi di kalangan masyarakat Indonesia. Perjalanan yang dinarasikan para bloggers maupun influencers (pemberi pengaruh) telah menciptakan tren gaya hidup tersendiri dan lebih jauh nilai-nilai yang berjalinan dengan budaya keseharian masyarakat. Penelitian ini menelaah narasi perjalanan bloggers di Instagram sebagai artefak tekstual untuk mendapatkan wawasan tentang bagaimana nilai dan budaya kehidupan manusia terajut dalam fenomena perjalanan. Penelitian ini menggunakan analisis semiotika yang dibaca lebih lanjut dengan menggunakan konsep Deleuze dan Guattari mengenai 'diri yang menjadi'. Penelitian ini berangkat dari asumsi narasi dan representasi yang dilihat sebagai perwakilan bentuk-bentuk politik molekuler yang menumbangkan identitas molar dan posisi tetap. Hasil dari peneltian ini menunjukan representasi perjalanan memperluas nilai kemandirian, kesendirian, individualisme, kreatifitas, bebas dan modern. Di mana perjalanan itu sendiri dilihat sebagai kebutuhan primer yang menyenangkan, ceria dan menenangkan. Lebih lanjut dalam kacamata ketidaksadaran masyarakat skizofrenik,
\end{abstract}


fenomena traveling yang termediasi oleh teks para bloggers menegaskan kehadiran subyek skizo. Subyek yang penuh paradoks, dimana gerakan kolektif melalui perjalanan merupakan gerakan bersama untuk menjadi sendiri.

Kata Kunci: Deleuze-Guattari, masyarakat informasi, media sosial, perjalanan, blog perjalanan

\section{Pendahuluan}

Wajah dinamika kehidupan sosial mengalami perubahan drastis dengan perkembangan pesat teknologi komunikasi dan informasi. Transformasi kehidupan sosial ini bahkan telah dilihat sebagai revolusi era kehidupan baru yang kerap didefinisikan dengan istilah masyarakat informasi. Masyarakat informasi tidak semata mengintensifikasi informasi, namun juga menjalin praktik komunikasi, media, budaya, dan masyarakat dalam satu entitas. Dalam konteks masyarakat informasi semacam ini, berbagai fenomena sosial lahir sebagai wujud perubahan dan kultur baru hidup keseharian masyarakat global. Turkel (1995, 2005) bahkan memaparkan mengenai perubahan cara berpikir dan perilaku manusia dengan teknologi mendorong evolusi keterbelahan diri.

Seiring dengan perluasan aktifasi informasi dan teknologi komunikasi di tengah masyarakat, aktifitas wisata (travelling) melejit sebagai budaya dan gaya hidup masyarakat global, termasuk di Indonesia. Fenomena berwisata tidak dapat dilepaskan dengan titik tolak kapitalisme tingkat lanjut, masyarakat urban, dan secara manifest gerakan ekonomi kreatif yang berlangsung secara global.

Hasil studi GTIS 2015 menyatakan frekuensi perjalanan orang Indonesia akan mengambil rata-rata lima perjalanan dalam dua tahun ke depan, lebih banyak dari rata-rata global yaitu tiga perjalanan (Hermawan, 2017). Fenomena travelling secara gamblang melesat sebagai gaya hidup di Indonesia beriringan dengan perkembangan media, yang memaparkan daya tarik wisata dan menumbuhkan aspirasi untuk melakukan perjalanan. Indikator perjalanan yang meningkat juga dapat dilihat dengan pertumbuhan fasilitas perjalanan, yang menurut Badan Pusat Statistik (BPS), pada kuartal tiga 2017, restoran dan hotel tumbuh signifikan dibanding kuartal tiga 2016, dengan pertumbuhannya di 5,52\%. Peningkatan travel sebagai bagian dari gaya hidup warga Indonesia, juga didukung oleh angka transaksi online di berbagai aplikasi perjalanan yang menunjukan bahwa pola konsumsi masyarakat Indonesia bergeser dari non-leisure ke leisure. Di Shopback, sebuah perusahaan yang berpusat di Singapore, tingkat pemesanan untuk tiket dan hotel pada kuartal satu 2018 meningkat 6\% dibanding kuartal yang sama di tahun sebelumnya (BussinesNews,2018). Paparan riset di Middle Class Institute (MCI) juga menunjukan di 9 kota besar di Indonesia, kelas menengah mengalokasikan pengeluaran untuk liburan rata-rata 7,3\% per bulan (Yuswohadi dan Gani, 2015).

Peningkatan fenomena traveling sebagai bagian dari gaya hidup di Indonesia berjalan seiring dengan perkembangan media massa online. Aktifitas perjalanan tidak hanya meningkat karena jumlah eksposure berbagai perjalanan wisata yang massif, namun juga tingginya informasi dan aplikasi perjalanan yang berkembang lebih memudahkan akses warga dalam mengatur wisata. 
Dian Arymami: Diskoneksi Nomad: Paradoks Kemenjadian dalam Sosial Media bertema Travelling

Perkembangan media baru juga meningkatkan informasi pengalaman wisata yang kian persuasif dengan sifat media baru yang serat dengan pengalaman personal warganet.

Akselerasi aktifitas travelling di tengah aktifisme media informasi masyarakat, telah membawa perluasan informasi wisata yang terpersonalisasi. Baik sebagai bagian dari pertumbuhan audiens aktif yang memungkinkan konsumen media sekaligus sebagai produsen pesan, maupun perkembangan konten sebagai bagian dari perluasan strategi pemasaran muktahir. Travel writing mengalami akselerasi dan perluasan dalam fenomena pergerakan informasi dan konvergensi media.

Travel writing pada dasarnya adalah sebuah upaya untuk mendokumentasikan perjalanan dalam bentuk yang lebih detail, yaitu foto dan reportase, di mana para pelakunya dikenal dengan sebutan travel writer (Yudasmoro, 2012). Aksesibilitas media baru juga telah mengembangkan bentukbentuk baru dari jurnal-jurnal perjalanan seperti blog dan vlog. Travel Writing pun mengikuti dan menyesuaikan berbagai karakteristik platform digital media baru yang berkembang dan diminati masyarakat.

Dalam perkembangan terbaru, tulisan mengenai travelling dari warga masyarakat melahirkan berbagai travel writers/blogger di media baru yang kemudian menjadi bagian dari industri wisata yang lebih luas melalui konten promosi serta narasi perjalanan personal. Indonesia mungkin mulai mengenal travelling blog dari nama Trinity yang menulis The Naked Traveller. Kekuatan wacana dan tren perjalanan tidak dapat dipandang sebelah mata dari para pelancong Indonesia, melihat fakta bahwa salah satu populasi warganet terbesar maupun penulis travellers di Asia Tenggara adalah Indonesia. Tema travelling juga menjadi isu yang dominan mengisi wacana konten warganet di media baru. Popularitas isu perjalanan lebih banyak daripada tema populer lain seperti makanan, kecantikan, mode, teknologi maupun bisnis. Dari 50 blog teratas tahun 2018 di Indonesia, terdapat 20 blog tertinggi bertema perjalanan (ASEANUP, 2018). Dalam liris ini juga menggambarkan bagaimana lalu lintas situs per bulan di blog-blog tersebut menunjukan angka yang fantastis; "travellingyuk" misalnya per bulannya mencapai hingga $1,020,000$ akses, dengan jumlah anggota komunitas mencapai 1,798,000 anggota.

Dinamika wacana perjalanan dan wisata juga mendorong bisnis-bisnis online secara pesat. Pada tahun-tahun belakang ini, aplikasi wisata menjadi salah satu aplikasi tertinggi penggunaannya di Indonesia. Hal ini melingkupi aplikasi tiket pesawat, paket wisata, maupun hotel. Aplikasi bertema perjalanan seperti "triponyu" bahkan mendapatkan penghargaan sebagai start-up innovatif dari Indonesia oleh PBB pada awal tahun 2018. Travelling telah menjadi bagian dari kehidupan warga Indonesia yang berjalinan erat dengan ekologi komunikasi saat ini.

Fenomena perjalanan yang telah menjamur telah memantik berbagai studi dalam dasawarsa terakhir. Berbagai riset telah berkembang meneliti blog perjalanan dan media sosial yang terkait sebagai bentuk penyadaran dan presentasi diri yang menegosiasikan ketegangan antara wacana perjalanan dan pariwisata (Azariah, 2017; Galani-Moutafi, 2000). Selain itu, pendekatan ekonomi 
dan bisnis pemasaran kerap menjadi pendekatan dalam melihat fenomena ini, secara spesifik pada potensi konten travel writers untuk mempengaruhi perilaku perjalanan dan pengambilan keputusan. Faktanya memang aktivitas blogging di kalangan wisatawan meningkat dan mewakili aspek baru yang penting dari komunikasi pemasaran di bidang pariwisata. Perkembangan penelitian semacam ini, juga meliputi analisis webometric yang diusulkan terdiri dari formula terintegrasi termasuk visibilitas, popularitas, dan ukuran metrik. Metode ini digunakan untuk menentukan peringkat 11 situs yang sesuai untuk mempelajari kasus Catalonia seperti yang dilakukan oleh Marine-Roig (2014).

Lebih lanjut, wacana perjalanan melalui konten para bloggers maupun influencers (pemberi pengaruh) telah menciptakan tren gaya hidup tersendiri dan secara sublim menjalin nilai-nilai dalam budaya keseharian masyarakat. Kontenkonten perjalanan yang marak disiarkan melalui media sosial Instagram oleh para travel bloggers merupakan artefak tekstual yang signifikan. Karakteristik yang melekat pada media sosial ini, telah memadatkan narasi perjalanan diri personal melalui interkoneksi bahasa visual dan tekstual sekaligus merepresentasikan nilai dan budaya kehidupan manusia "modern" saat ini.

Diri merupakan subyek yang telah dilihat sebagai jantung dalam mendefinisikan kehidupan. Dalam Subjectivity karya Mansfield (2000) menggambarkan setidaknya ada empat ranah umum tipe subyek yang memberikan diversifitas perkembangan pemikiran atas diri, yakni; Subject of grammar, Politio-legal Subject, Philosophical Subject, dan Subject as Human person. Kompleksitas diri sebagai subyek menentukan bagaimana diri terdefinisikan dalam hubungan manusia dengan dunia. Hal ini pula yang meletakan distinksi diri dan yang liyan dalam satu pendulum dengan dua kutub. Dua titik ekstrim perkembangan pemikiran atas subyek terletak pada kutub subyektifitas dan anti-subyektifitas.

Konten perjalanan di media sosial merupakan representasi narasi perjalanan sekaligus menjadi representasi atas diri dalam kehidupan yang didefinisi oleh subyek. Di tengah ekologi masyarakat informasi saat ini, diri yang terserap dalam teknologi sebagaimana dihamparkan oleh berbagai karya mengenai manusia di tengah teknologi (Turkel, 1995, 2005; Schmidt, Eric \& Cohen, Jared, 2013) menjadi sosok-sosok yang terbelah.

Deleuze dan Guattari (1977) memaparkan pada titik ekstrim antisubyektifitas bagaimana diri dapat terberai dengan sifat multisiplitas merupakan sosok-sosok yang terus menjadi. Landasan diri yang terus menjadi merupakan pemikiran yang secara fundamental berangkat dari kritik atas konsep aboresence, sebuah struktur hirarkis pemahaman atas identitas, makna, dan kebenaran dalam kehidupan manusia yang stabil. Dalam kata-katanya; 'aboresence systems are hierarhical systems with centers of significance and subjectification, central automata like organised memories. In the corresponding models, an element only recieves information from a higher unit and only receives a subjective affection along pre-established paths' (Deleuze dan Gauttari 1977). Basis asumsi sistem hirarkis atas makna dan kebenaran yang secara sosio-historis dipelihara dalam kehidupan sosial merupakan bagian dari investasi sosial yang menjadi fokus kritik pemikiran Deleuze dan Gauttari (Mansfield, 2000). Konsep rhizome merupakan 
Dian Arymami: Diskoneksi Nomad: Paradoks Kemenjadian dalam Sosial Media bertema Travelling

tawaran Deleuze dan Guatari yang berkebalikan dengan konsep aboresence. Konsep ini merupakan basis dari hadirnya multiplisitas diri yang melahirkan diri dari kumpulan substansi yang imanen. Pemikiran Deleuze dan Guattari merupakan konsep filosofis kehidupan rumit yang hadir jauh sebelum masanya, kini tampak mengada dalam keseharian masyarakat informasi.

Pemaparan Deleuze dan Gauttari menggaris bawahi bahwa setiap individu dalam masyarakat bergerak dalam ketidaksadaran investasi sosial. Ketidaksadaran manusia membangun interaksi terbagi dalam konsep pergerakan masa oleh Deleuze yang disebut dengan 'The Molecular dan Molar Unconciousness'. Molekular menjelaskan pergerakan yang menuju pada penyatuan, sedangkan Molar menjelaskan pergerakan yang menuju pada perluasan masa. Segenap individu terlibat dalam arus hukum antara yang molekular dan molar yang berlangsung secara bersamaan di tengah ketidaksadaran investasi sosial. Seluruh investasi sosial merupakan hal yang kolektif, dimana posisi realitas menjadi fantasi yang kolektif.

Di tengah tingginya isu perjalanan dan gaya hidup berwisata, menarik untuk dapat memahami lebih lanjut mengenai dinamika nilai kapitalisasi budaya dalam wacana perjalanan. Dengan menggunakan kacamata Deleuze dan Guattari, narasi perjalanan dapat dilihat sebagai adalah tindakan politik yang disatu sisi menantang kekuasaan dan dominasi; menolak pemaksaan norma-norma dominan; deterritorialisasi di tengah mayoritas. Dalam sudut pandang ini, narasi menjadi proses identitas yang selalu berubah, potensi, dan juga "menjadi" (devenir). Sebuah gerakan tak terkendali dan deterritorialisasi, dicirikan oleh adanya perubahan abadi dan metamorfosis terus menerus. Ide yang tersimpan dalam wacana utama perjalanan semacam ini menjadi essensial dalam membaca konteks perkembangan interaksi dan psikososial masyarakat, yang utama dalam dinamika kehidupan sosial.

Konten perjalanan di media sosial yang diunggah oleh para travel writers dan influencers merupakan artefak tekstual yang dapat menggambarkan bagaimana posisi realitas diri dan kehidupan saat ini dalam narasi-narasi perjalanan. Dengan membedah unggahan travel bloggers dalam media sosial, nilai gaya hidup perjalanan dapat ditemukan dengan menyandingkan identitas diri dan komoditisasi perjalanan. Fenomena gaya hidup pelancong yang menjamur dalam media sosial menjadi signifikan dibedah.

\section{Metode Penelitian}

Penelitian ini menitik beratkan pada teks sebagai objek kajian, sekaligus menempatkan isi teks sebagai representasi ideologis. Keterkaitan isi teks sebagai representasi ideologis dimungkinkan untuk menggunakan analisis semiotika dengan meminjam pemikiran Ferdinand De Saussure (lihat Noth, 1990) dalam membedah nilai gaya hidup bertema travelling yang dipilih. Obyek kajian yang akan ditelaah dalam penelitian ini terkerucut melalui medium visual yang tersiarkan melalui media sosial Instagram sebagai salah satu media paling populer saat ini. Akun travel blogger yang dipilih berbasis pada jumlah popularitas dengan mempertimbangkan diversitas latar belakang blogger untuk mendapatkan 
gambaran yang lebih holistik. Kajian obyek akun Instagram juga hanya akan mengambil unggahan pada tahun 2018, dengan masing-masing tiga posting dengan pergantian lokasi terakhir. Dari daftar sebelas travel blogger terpopuler di Indonesia tahun 2018 (lihat tabel 1), akun dengan rerata followers yang berada di atas 30 ribu dan dibawah 90 ribu followers akan dijadikan obyek penelitian. Dengan demikian mendapatkan tiga akun yang terdiri dari IG: Kartupos, Pergidulu dan Catperku.

Tabel 1. Daftar Travel Blogger Terpopuler Indonesia 2018

\begin{tabular}{|c|c|c|c|c|c|}
\hline 1 & $\begin{array}{l}\text { Marischka Prudence } \\
\text { IG/marischkaprue } \\
\text { Followers: } 108 \text { ribu }\end{array}$ & 2 & $\begin{array}{l}\text { Alexander Thian } \\
\text { IG/amrazing } \\
\text { Followers: } 292 \text { ribu }\end{array}$ & 3 & $\begin{array}{l}\text { Windy Ariestanty } \\
\text { IG/windy_ariestanty } \\
\text { Followers: } 21 \text { ribu }\end{array}$ \\
\hline 4 & $\begin{array}{l}\text { Trinity } \\
\text { IG/trinitytraveler } \\
\text { Followers: } 92,5 \text { ribu }\end{array}$ & 5 & $\begin{array}{l}\text { Agustinus Wibowo } \\
\text { IG/avgustin } 88 \\
\text { Followers: } 7,251\end{array}$ & 6 & $\begin{array}{l}\text { Kartu Pos } \\
\text { IG/kartuposinsta } \\
\text { Followers: 53,6 ribu }\end{array}$ \\
\hline 7 & $\begin{array}{l}\text { Dua Ransel } \\
\text { IG/duaransel } \\
\text { Followers: } 17,2 \text { ribu }\end{array}$ & 8 & $\begin{array}{l}\text { Bowo Hartanto } \\
\text { IG/traveljunkieid } \\
\text { Followers: } 8,547\end{array}$ & 9 & $\begin{array}{l}\text { PergiDulu } \\
\text { IG/pergidulu } \\
\text { Followers: } 58,7 \mathrm{ribu}\end{array}$ \\
\hline 10 & $\begin{array}{l}\text { M. Takdis } \\
\text { IG/takdos } \\
\text { Followers: } 20,1 \mathrm{ribu}\end{array}$ & 11 & $\begin{array}{l}\text { Rijal Fahmi M. } \\
\text { IG/catperku } \\
\text { Followers: } 33,7 \mathrm{ribu}\end{array}$ & & \\
\hline
\end{tabular}

Sumber: Utari (24 Juli, 2018)

Alur pengolahan data dalam penelitian ini dapat dilihat dalam gambar alur di bawah ini:

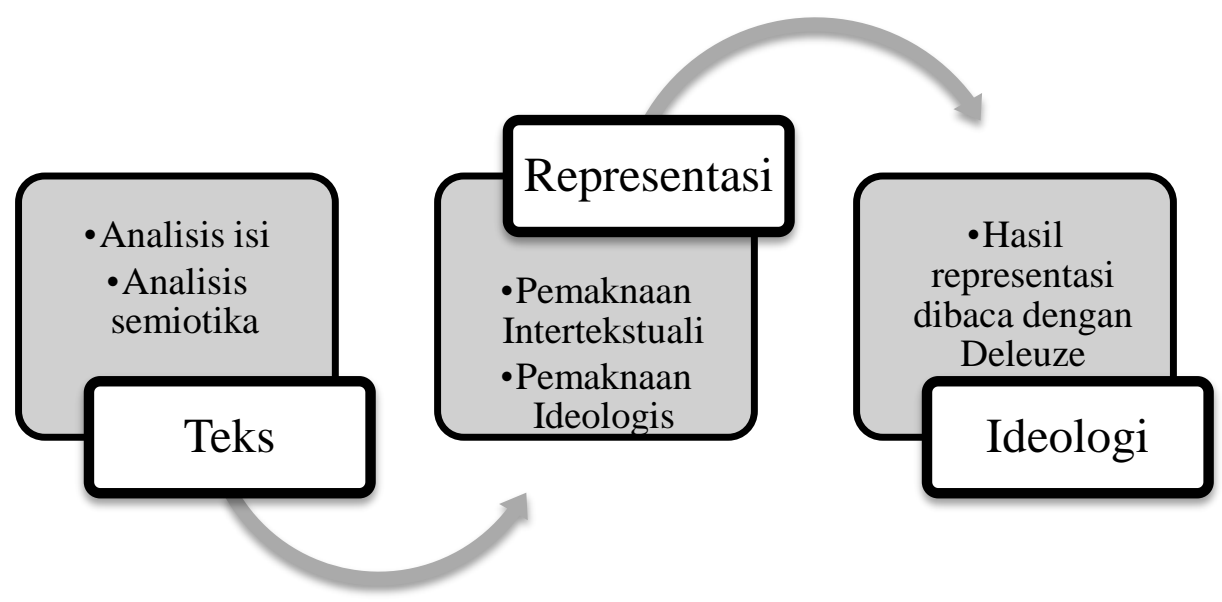

Pada tahapan pertama. data teks Instagram travel bloggers yang dikaji meliputi foto dan caption foto. Analisis isi dilakukan dengan mengkategorikan dan mencari generalisir penggunaan komposisi, warna, point of interest (POI) dan latar. Sedangkan data tekstual dikategorikan dan dicari generalisir pada jenis pesan yang masuk dalam travelouge yakni; pengalaman perjalanan, tips perjalanan, aspirasi/motivasi dan komersialisasi. Pada tahap ke-dua, representasi dilakukan dengan membaca intertualitas antara visual dan keterangan tekstual 
Dian Arymami: Diskoneksi Nomad: Paradoks Kemenjadian dalam Sosial Media bertema Travelling

untuk mendapatkan konotasi, kesan, dan pesan dibalik gambar dan kata-kata. Pemaknaan atas gabungan petanda ini menjadi pintu masuk untuk mengulas ideologi dan nilai yang terkandung dalam unggahan teks. Selanjutnya, pada tahap ke-tiga, hasil dari representasi dan pemaknaan temuan akan dibaca dengan menggunakan logika pemikiran Deleuze dan Guattari mengenai masyarakat skizofrenik yang tampak kontekstual dalam era komunikasi digital. Bacaan ini menjadi upaya untuk mendorong lebih lanjut prediksi kritis atas nilai-nilai yang bergerak di dalam masyarakat berhubungan dengan fenomena perjalanan yang eksplosif di Indonesia.

\section{Hasil Penemuan dan Diskusi}

Pengguna Instagram di Indonesia merupakan salah satu populasi terbesar warga Instagram. Instagram mengklaim bahwa total pengguna yang melakukan login mencapai 300 juta per bulannya. Sedangkan pengguna aktif per bulannya diklaim berjumlah 284 juta. Jumlah tersebut mengalami peningkatan signifikan. Sebab, pada 2013, pengguna aktif per bulannya hanya 150 juta. Lembaga riset eMarketer menyatakan pengguna Instagram didominasi anak muda berusia 18-24 tahun (tekno.tempo.co, 2014).

Di Indonesia, Instagram menjadi salah satu media sosial favorite untuk mengunggah foto. Pada prakteknya, Instagram dapat dilihat sebagai sebuah jurnal pribadi yang berbentuk album foto virtual para penggunanya, dimana mereka dapat mengunggah foto apapun yang mereka inginkan, kapanpun, menentukan lokasi foto dimanapun, serta menuliskan judul foto atau caption apapun. Sehingga konsekuensi di dalamnya, media sosial layaknya Instagram seringkali di manfaatkan sebagai ajang arena memproduksi realitas yang termediasi melalui citra visual foto.

Fenomena travelling telah menjadi bagian dari gaya hidup masyarakat Indonesia yang gamblang terlihat dalam berbagai eksposur dokumentasi personal yang tersiar melalui berbagai media sosial. Bahkan, tak sedikit ulasan mengenai fenomena warga Indonesia yang berlomba-lomba mengunggah pengalaman wisatanya di akun media sosialnya; mulai dari selfie di tempat wisata, tetapi juga situasi sekitarnya termasuk obyek wisata, kuliner, fashion, dan lain sebagainya. Berbagai sosok yang ditemukan rajin mengunggah konten tentang perjalanan secara konsisten, cukup dikenal dan tidak sedikit beralih profesi menjadi travel blogger. Profesi sebagai travel blogger pun tak elak naik daun sebagai influencer yang didukung oleh berbagai merek industri perjalanan. Dinamika keternamaan travel blogger Indonesia di jagat dunia maya pun bergeser dari tahun ke tahun. Dalam rangka melihat lebih jauh mengenai representasi gaya hidup yang direpresentasikan dalam medium travel blogger via Instagram, obyek kajian dalam penelitian ini meliputi sembilan foto dari tiga akun travel blogger berbeda, dengan pembahasan sebagai berikut: 


\section{Visual dan Teks Travel Blog dalam Instagram}

Unggahan Instagram para travel bloggers dalam akun personal menunjukan kecenderungan karakteristik gambar (lihat tabel 2). Pada tataran visual bisa dibedah melalui beberapa elemen pengambilan shot, lighting/pewarnaan, titik fokus/obyek, dan latar. Sedangkan dalam tataran teks, beberapa elemen yang pesan dapat dikategorikan dalam kecenderungan pengalaman, tips, persuasi maupun penjualan.

Tabel 2. Obyek Penelitian

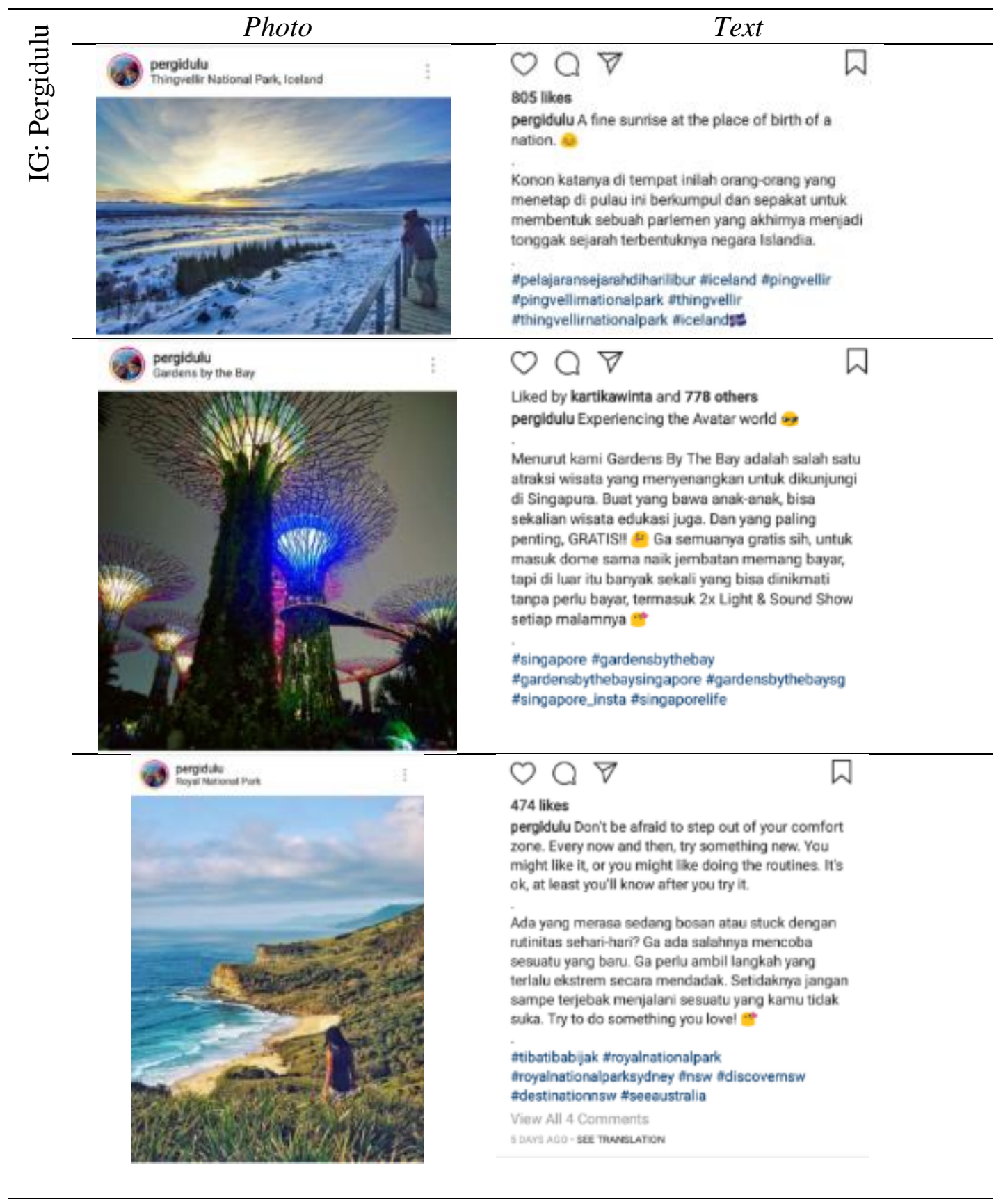


Dian Arymami: Diskoneksi Nomad: Paradoks Kemenjadian dalam Sosial Media bertema Travelling

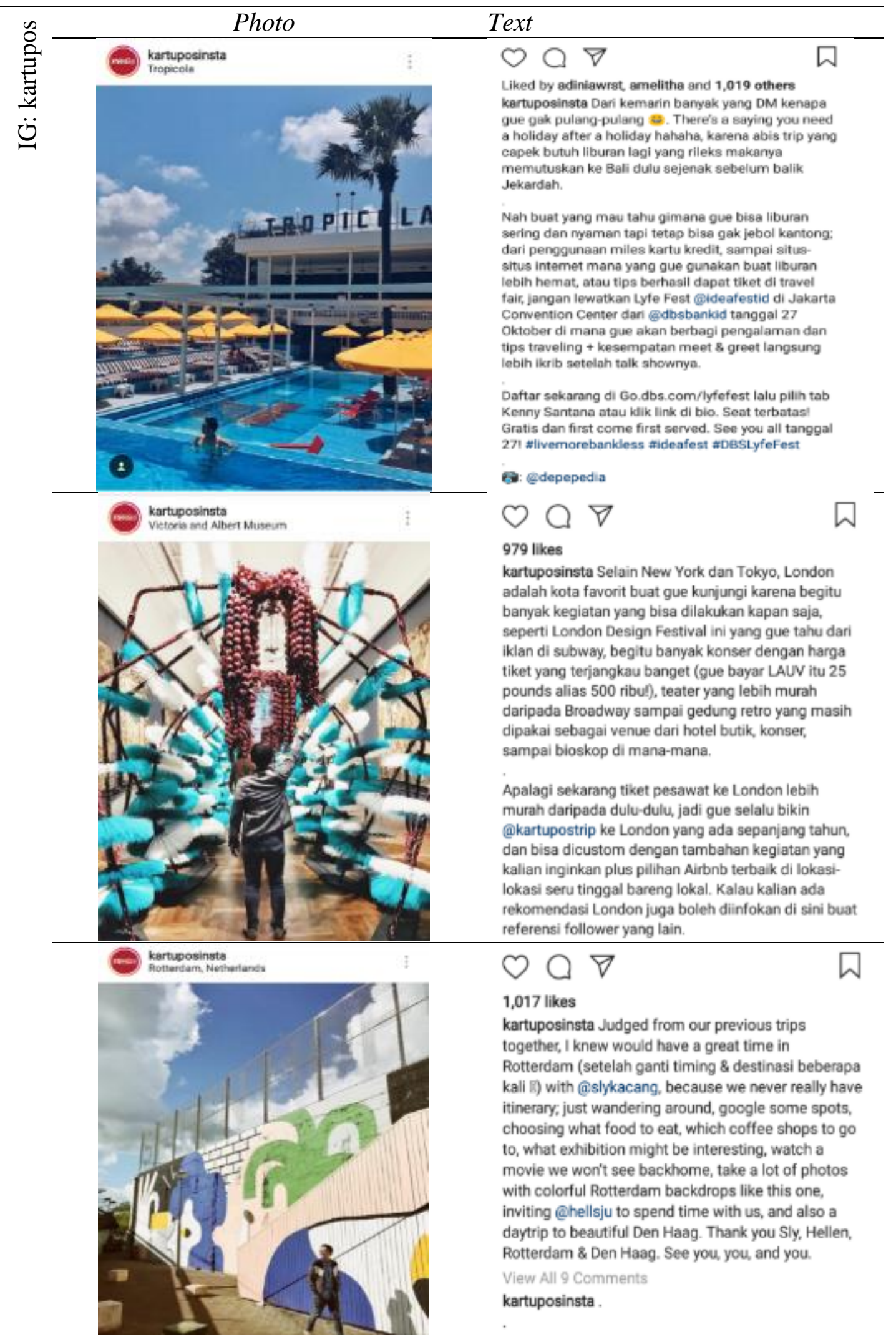




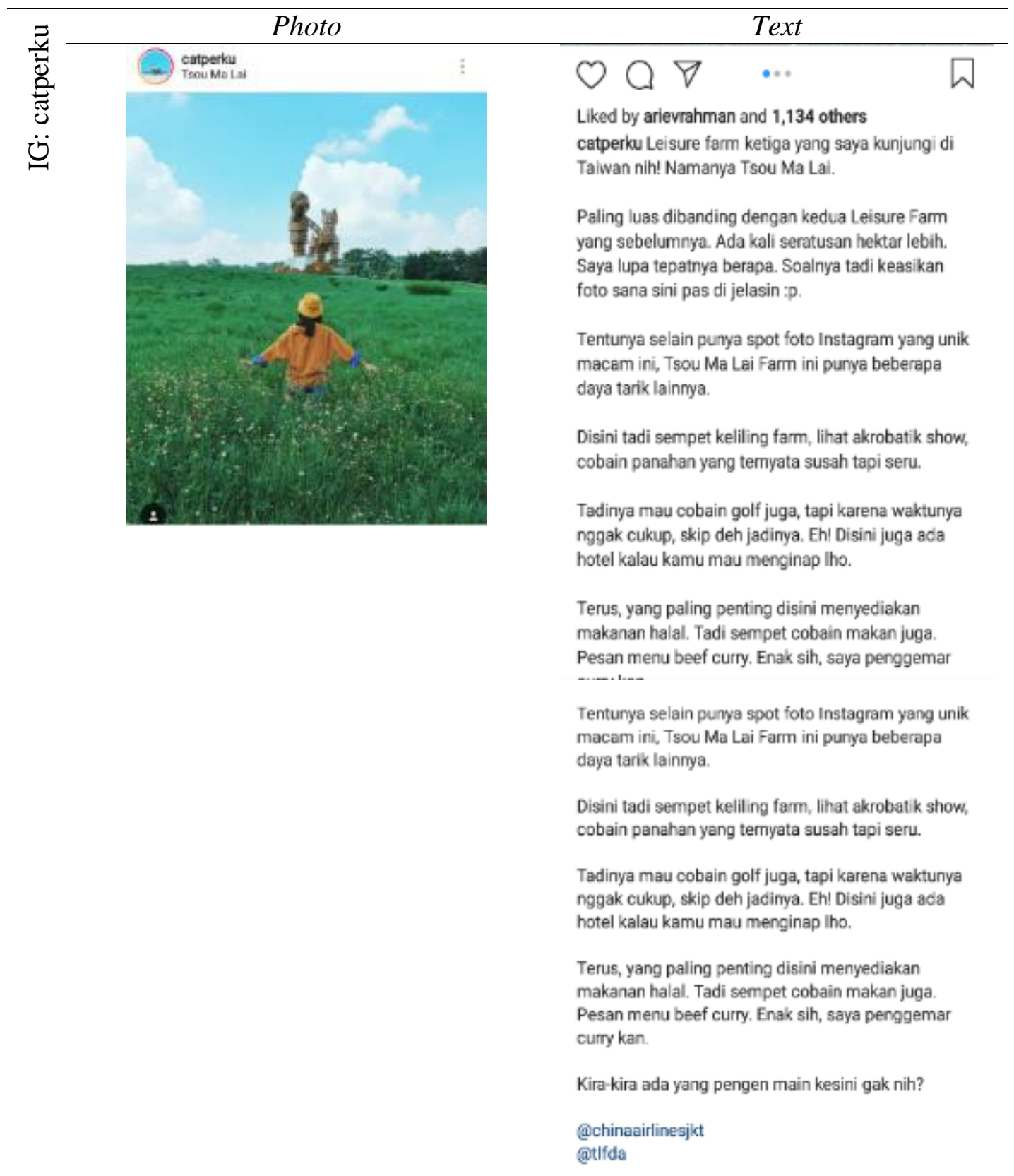


Dian Arymami: Diskoneksi Nomad: Paradoks Kemenjadian dalam Sosial Media bertema Travelling

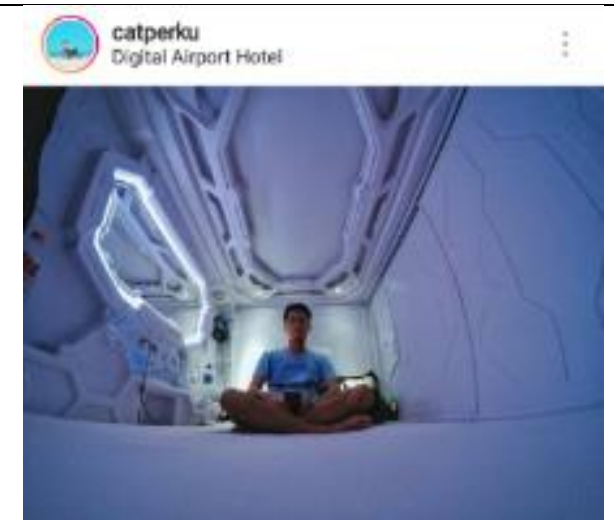

\section{1,230 likes}

catperku Jadi beberapa waktu lalu saya sempat mendengar ada hotel kapsul baru dengan desain yang futuristik di Bandara Soekamo Hatta Terminal 3.

Kebetulan kemarin saya ada penerbangan dari Jakarta. Karena saya berangkat dari Blitar dan sampai Jakarta pagi banget.

Karena ada waktu sekitar 7 jam transit, saya pun sekalian mencoba hotel kapsul ini. Penasaran sih kalau baca-baca reviewnya. Katanya bagus gitu.

Ternyata setelah mencoba, lumayan lah kalau untuk transit. Kapsulnya bersih, fasilitasnya oke, dan lokasinya di Bandara. Gak perlu lagi cari hotel di luar Bandara.

Ada yang udah cobain juga? Menurut pendapat kalian gimana mengenai hotel kapsul bandara ini?

Saya juga bikin vlog reviewnya lho di youtube.com/ catperku. Tonton ya! Link aktif di BIO, jangan lupa like, share and subscribe!

\#catperku \#catperkuinjava \#catperkureview \#explorejakarta \#jakarta \#digitalairporthotel thandarasoekarnohatta

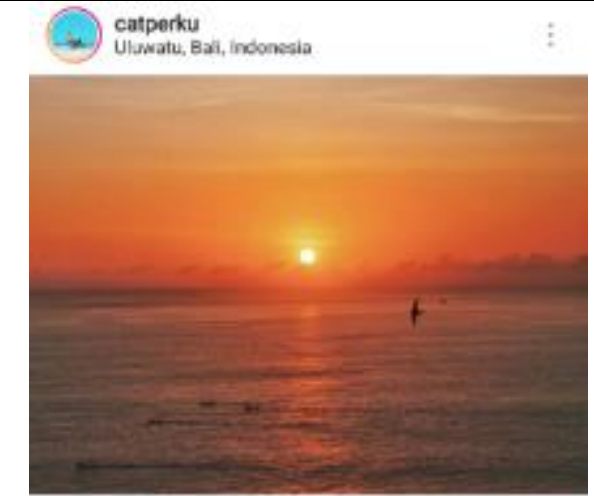

$\bigcirc \bigcirc \nabla$

682 likes

catperku "No words can describe such a beautifu sunset"

Ini pemandangan sunset di Uluwatu beberapa tahun lalu :) Sunset di Bali emang selalu cakep n gak ngebosenin.

Eh, kalau sunset terbaikmu lihat dimana? Share dong!

\#catperku \#catperkuinbali \#explorebali \#balidaily \#bali $\#$ \#balitrip

\section{Visualisasi Unggahan di Instagram Travel bloggers}

a. Pengambilan Shot

Dari 9 unggahan Instagram dengan lokasi pengambilan berbeda menunjukan kesamaan pada jenis pengambilan shot yang didominasi oleh pengambilan medium shot. Delapan dari sembilan gambar menunjukan komposisi medium shot dan satu gambar diambil dengan longshot. Komposisi dalam foto-foto di dominasi oleh komposisi sederhana berbasis Aturan Pertiga dan komposisi Simetri/Tengah. Komposisi aturan pertiga merupakan cara sederhana meletakan POI (point of interest) melalui kreatifitas dan permainan berdasarkan pada pembagian gambar yang terdiri dari 3 bagian vertikal dan 3 bagian horizontal. Cara ini memudahkan untuk membuat komposisi lebih rapi dan pergeseran POI di luar kotak tengah senantiasa memberikan perspektif yang unik. Pada akun @ pergidulu dan @kartupos, seluruh foto unggahan menggunakan teknik 
Aturan Pertiga, sedangkan akun@catperku seluruh foto menggunakan teknik simetri. Teknik simetri merupakan cara pengambilan foto dengan meletakan POI pada posisi tengah frame atau tepat di sentral. Kedua jenis teknik komposisi gambar ini tak elak memberikan kesan yang berbeda. Komposisi aturan pertiga memberikan kesan yang lebih dinamis dan fleksibel, sedangkan komposisi simetri menegaskan kesan kaku, kuat dan stabil.

b. Lighting dan Pewarnaan

Kecenderungan pewarnaan dari unggahan Instagram travel bloggers adalah dengan tone dingin alih-alih hangat. Warna-warna hangat merupakan warna-warna yang berada pada rentang spektrum warna kemerahan. Sedangkan warna dingin merupakan warna-warna yang berada pada rentang spektrum warna biru. Dengan demikian foto unggahan mayoritas didominasi oleh sifat dingin yang berada di spektrum warna biru. Kesan dari sifat warna hangat dan dingin berpengaruh pada pesan visual. Warna-warna dalam sifat hangat, memberikan kesan hangat, ceria, cerah dan bahkan amarah, tergantung pada intensitas penggunaannya. Sedangkan warna dengan sifat dingin memberikan kesan tenang, luas, lapang, sepi, sedih, sunyi, professional dan mapan tergantung dengan intensitas penggunaan warna birunya.

c. Fokus/Obyek/ Point of Interest (POI)

Fokus gambar merupakan titik utama sebuah foto, dimana ia menjadi inti dari cerita/kisah yang disampaikan. Titik fokus sebuah foto dapat memberikan konteks foto secara keseluruhan bagi audiensnya. POI senantiasa berkaitan juga dengan komposisi foto. Pada unggahan foto travel blogger di atas, ada kecenderungan fokus atau obyek foto didominasi oleh sosok manusia. Dari 9 foto, tujuh diantaranya memiliki sosok manusia sebagai fokus gambar. Sedangkan 6 dari tujuh foto yang memiliki fokus sosok manusia, hanya satu yang menunjukan gambar dan ekspresi wajah secara jelas. Sosok manusia sebagai fokus dalam 6 foto lainnya menggambarkan aktifitas, baik memandang maupun berjalan. Dua foto yang tidak meletakan sosok manusia sebagai Point of Interest, menyerahkan fokusnya pada obyek alam dan arsitektur gedung.

d. Latar

Latar merupakan lanskap atau bagian yang melingkupi sekitar POI/ fokus obyek foto. Latar dapat memberikan konteks atas pesan foto yang disampaikan. Latar dari unggahan foto para travel bloggers di atas terdiri dari latar alam dan lokasi buatan manusia (bangunan/gedung/seni). Lima dari 9 foto memberikan latar lokasi buatan manusia dan 4 diantaranya memberikan gambaran latar alam. Semua travel blogger memiliki unggahan berlatar lokasi buatan manusia yang menonjolkan arsitektur dan serat kesenian atau kreatifitas buatan manusia. Latar foto yang memberikan gambaran tentang lokasi buatan manusia, menonjolkan keunikan lokasi yang memberikan kesan extra-ordinary; dengan kata lain keunikannya bukan menjadi pemandangan yang umum dan mudah ditemukan. Pilihan latar merupakan land-mark atau bangunan ikonik 
Dian Arymami: Diskoneksi Nomad: Paradoks Kemenjadian dalam Sosial Media bertema Travelling

wilayah. Selain itu, ada kesan atas modernitas sekaligus kreatifitas yang erat dengan seni. Foto 'Garden by the Bay', misalnya merupakan bangunan ikonik yang lekat dengan negara Singapura, kompleksitas arsitektur gedung ini pun memberikan kesan seni yang tinggi dan modernitas yang terkini. Terlepas dari gedung-gedung ikonik atau landmark, berbagai unggahan yang berlatar buatan manusia memberikan gambaran atas kreatifitas dan dinamis.

Penggunaan bahasa visual sebagai teks (unggahan) utama travel blogers di akun Instagramnya dapat di rangkum pada tabel 3 di bawah ini;

Tabel 2. Rangkuman karakteristik foto

\begin{tabular}{clllll}
\hline akun & & \multicolumn{1}{c}{ Shot } & Sifat Warna & \multicolumn{1}{c}{ POI } & \multicolumn{1}{c}{ Latar } \\
\hline Pergidulu & 1 & Medium $-1 / 3$ & Dingin & Manusia & Alam \\
\cline { 2 - 6 } & 2 & Medium $-1 / 3$ & Dingin & Tiang & banungan \\
\cline { 2 - 6 } & 3 & Medium $-1 / 3$ & dingin & Manusia & Alam \\
\hline Kartupos & 1 & Medium $-1 / 3$ & Dingin & Manusia & bangunan \\
\cline { 2 - 6 } & 2 & Medium $-1 / 3$ & Dingin & Manusia & bangunan \\
\cline { 2 - 6 } & 3 & Medium $-1 / 3$ & Dingin & Manusia & bangunan \\
\hline Catperku & 1 & Medium $-1 / 3$ & Dingin & Manusia & Alam \\
\cline { 2 - 6 } & 2 & Medium $-1 / 3$ & Dingin & Manusia & bangunan \\
\cline { 2 - 6 } & 3 & Longshot & hangat & matahari & Alam \\
\hline
\end{tabular}

\section{Intertekstualitas Visual dan Teks Unggahan di Instagram Travel bloggers}

Caption atau penjelasan tekstual di bawah unggahan foto Instagram dapat digunakan untuk menerangkan unggahan atau melengkapi pesan secara keseluruhan. Dari keterangan yang tertulis secara tekstual para unggahan travel bloggers di atas, ada beberapa kategori pesan teks yang dapat dirangkumkan, sebagai berikut:

a. Pengalaman

Berbagi mengenai kesan personal atau pengalaman perjalanan merupakan bagian besar dari pesan travel bloggers. Penggunaan kata orang pertama merupakan pilihan bahasa yang paling sederhana dalam menegaskan pengalaman personal. Hal ini juga menjadi pilihan dominan yang digunakan dalam penulisan tekstual unggahan foto di akun Instagram di atas. Dari tiga akun Instagram travel bloggers di atas, di dominasi oleh penggunaan orang pertama dan mengutarakan pengalaman personal. Dua diantaranya (@kartupos dan @ catperku) cenderung menggunakan pilihan orang pertama dalam captionnya, sedangkan @ pergidulu mayoritas tidak memilih meletakan kalimat informatif daripada sudut pandang orang pertama.

b. Informasi/Tips Traveling

Informasi baik seputar wilayah perjalanan maupun saran perjalanan menjadi bagian dari pesan utama peran travel bloggers. Informasi berpadu 
dengan pengalaman perjalanan kerap digunakan dalam mendeskripsikan gambar.

c. Aspirasi/Motivasi

Pesan-pesan aspiratif mengarahkan pada emosi audiens untuk turut mengajak melakukan aktifitas tertentu. Baik kalimat yang mengulik emosi-emosi personal seperti kelelahan berada di arena comfort zone berlebihan menjadi bagian dari pesan-pesan aspiratif dalam unggahan travel bloggers. Dari keterangan foto-foto di atas, pesan-pesan aspiratif dan motivasi tidak terlalu banyak ditemukan dalam bauran pesan informasi mengenai perjalanan. Meski demikian, pesan-pesan motivasional semacam ini lebih cenderung digunakan oleh travel bloggers sebagai keterangan pada foto tambahan berseri. Maksudnya menjadi caption dari foto kesekian dari satu tempat yang dikunjungi.

d. Komersialisasi/Penjualan

Pesan-pesan teks yang mengarah pada komersialisasi dapat ditemukan dalam teks pengiring unggahan foto dalam akun Instagram. Pesan komersial yang dimaksudkan merupakan kalimat-kalimat lugas yang menyebutkan merek atau mengarahkan pada penjualan dan konsumsi tertentu. Tidak sedikit pesan-pesan komersial juga menjadi bagian dari promosi laman sosial blogger lainnya; seperti mengarahkan ke akun Youtube untuk vlog atau situs.

Penggunaan bahasa tekstual sebagai keterangan unggahan foto merupakan pelengkap dari keseluruah pesan teks (unggahan) travel blogers di akun Instagramnya. Jenis pesan tekstual dalam rangkuman dapat dilihat di tabel 4 di bawah ini:

Tabel 4. Rangkuman pesan Tekstual

\begin{tabular}{|c|c|c|c|c|c|}
\hline akun & & Pengalaman & Info./tips & Aspirasi & Penjualan \\
\hline \multirow{3}{*}{ Pergidulu } & 1 & & $\sqrt{ }$ & & \\
\hline & 2 & $\sqrt{ }$ & & & \\
\hline & 3 & & & $\sqrt{ }$ & \\
\hline \multirow[t]{3}{*}{ Kartupos } & 1 & $\sqrt{ }$ & $\sqrt{ }$ & $\sqrt{ }$ & $\sqrt{ }$ \\
\hline & 2 & $\sqrt{ }$ & $\sqrt{ }$ & & $\sqrt{ }$ \\
\hline & 3 & $\sqrt{ }$ & & & \\
\hline \multirow[t]{3}{*}{ Catperku } & 1 & $\sqrt{ }$ & $\sqrt{ }$ & & $\sqrt{ }$ \\
\hline & 2 & $\sqrt{ }$ & & & \\
\hline & 3 & & $\sqrt{ }$ & & \\
\hline
\end{tabular}

\section{Representasi Travel bloggers}

Dari paparan data visual dan teks unggahan Instagram para travel blogger, representasi sifat dan pemaknaan dapat dirangkum sebagai berikut; 
Dian Arymami: Diskoneksi Nomad: Paradoks Kemenjadian dalam Sosial Media bertema Travelling

Tabel 5. Rangkuman representasi dan pemaknaan

\begin{tabular}{|c|c|c|c|}
\hline$@$ & St & er & \\
\hline \multirow{3}{*}{ 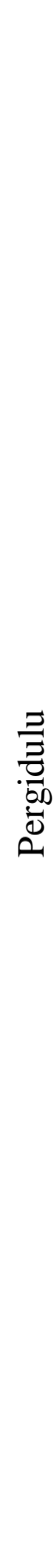 } & $\begin{array}{l}\text { Foto seorang yang sedang } \\
\text { berdiri sembari } \\
\text { memandangan lanskap } \\
\text { dan matahari terbit di } \\
\text { Iceland. Semburat cahaya } \\
\text { dari matahari tampak } \\
\text { pada sudut berlawanan } \\
\text { dengan sosok yang } \\
\text { memandang. Sifat warna } \\
\text { foto adalah dingin dengan } \\
\text { komposisi aturan } \\
\text { sepertiga. }\end{array}$ & $\begin{array}{lr}\text { Teks } & \text { menjelaskan } \\
\text { lokasi } & \text { dan } \\
\text { memberikan } \\
\text { informasi historis } \\
\text { mengenai tempat } \\
\text { tersebut. }\end{array}$ & $\begin{array}{lr}\text { Perpaduan } & \text { teks } \\
\text { memberikan kesan elegan. } & \text { Ada sifat individual dan } \\
\text { Ada } & \text { insendirian yang tersirat di } \\
\text { kesana. Kenikmatan } & \text { dan } \\
\text { keindahan } & \text { dalam } \\
\text { kesendirian serta } & \text { nilai } \\
\text { kebebasan. } & \end{array}$ \\
\hline & $\begin{array}{l}2 \text { Foto menunjukan tiang- } \\
\text { tiang ikonik Garden Bay } \\
\text { Singapore yang kompleks } \\
\text { dengan semburat warna } \\
\text { warni cahaya. Komposisi } \\
\text { foto menggunakan aturan } \\
\text { sepertiga dengan sifat } \\
\text { warna dingin. }\end{array}$ & $\begin{array}{lr}\text { Teks } & \text { memaparkan } \\
\text { informasi mengenai } \\
\text { Garden } & \text { Bay } \\
\text { Singapore } & \text { sebagai } \\
\text { tempat } & \text { wisata } \\
\text { ikonik } & \text { Singapura } \\
\text { yang rang } & \text { ramah } \\
\text { keluarga. } & \text { Selain } \\
\text { juga menyisipkan } \\
\text { informasi mengenai } \\
\text { biaya menikmati } \\
\text { fasilitas di tempat } \\
\text { tersebut. }\end{array}$ & $\begin{array}{l}\text { Pesan dari keseluruhan } \\
\text { memberikan nuansa } \\
\text { blogger sebagai sosok yang } \\
\text { aktif, melihat Singapura } \\
\text { sebagai salah satu terminal } \\
\text { transit terbesar di wilayah } \\
\text { Asia. Dan juga memberikan } \\
\text { kesan kekinian. Nuansa dan } \\
\text { sifat kokoh serta kreatif } \\
\text { tersirat melalui visualisasi } \\
\text { gambar yang terkoneksi } \\
\text { dengan para travellers. }\end{array}$ \\
\hline & $\begin{array}{l}\text { Seorang perempuan yang } \\
\text { sedang berjalan menuruni } \\
\text { bukit dengan latar } \\
\text { pemandangan pantai di } \\
\text { kejauhan. Bukit dipenuhi } \\
\text { oleh rerumputan yang } \\
\text { hijau, memberikan kesan } \\
\text { segar. Komposisi gambar } \\
\text { menggunakan aturan } \\
\text { sepertiga dan bernuansa }\end{array}$ & $\begin{array}{lr}\text { Teks sepenuhnya } \\
\text { mengandung } & \text { pesan } \\
\text { aspiratif } & \text { yang } \\
\text { mengajak } & \text { audiens } \\
\text { untuk } & \text { melepas } \\
\text { kepenatan } & \text { dan } \\
\text { mengerjakan } & \\
\text { aktifitas } & \text { yang } \\
\text { digemari. } & \end{array}$ & \begin{tabular}{lr} 
Gambar & \multicolumn{2}{c}{ seorang } \\
perempuan & sendiri yang \\
berjalan di & lanskap luas \\
mengesankan & kebebasan. \\
Perpaduan & penjelasan \\
tekstual & menegaskan \\
mengenai & pesan \\
'menikmati & aktifitas yang \\
dicintai'. &
\end{tabular} \\
\hline 窇 & $\begin{array}{l}1 \text { Foto menunjukan seorang } \\
\text { lelaki tengah berendam di } \\
\text { kolam renang dengan } \\
\text { lanskap bangunan hotel. } \\
\text { Gambar dengan shot } \\
\text { medium dan komposisi } \\
\text { aturan sepertiga } \\
\text { didominasi sifat warna } \\
\text { dingin dan semburat } \\
\text { kuning memberikan } \\
\text { nuansa ceria. }\end{array}$ & $\begin{array}{lr}\text { Teks menjelaskan } \\
\text { mengenai } \\
\text { kebutuhan liburan } \\
\text { dan } r \text { pesan } \\
\text { komersial untuk } \\
\text { menginap di hotel } \\
\text { dan mengikuti } \\
\text { program } \\
\text { perjalanan. }\end{array}$ & $\begin{array}{lrr}\text { Teks secara penuh } \\
\text { memberikan kesan atas } \\
\text { kenikmatan dan kebutuhan } \\
\text { untuk waktu luang dan } \\
\text { liburan. Ada kesan } \\
\text { kenikmatan pada aktifitas } \\
\text { bersantai, } & \text { selain } \\
\text { kesendirian } & \text { yang } \\
\text { tergambarkan } & \text { juga } \\
\text { memberikan kesan } & \text { nilai } \\
\text { kebebasan personal. }\end{array}$ \\
\hline
\end{tabular}




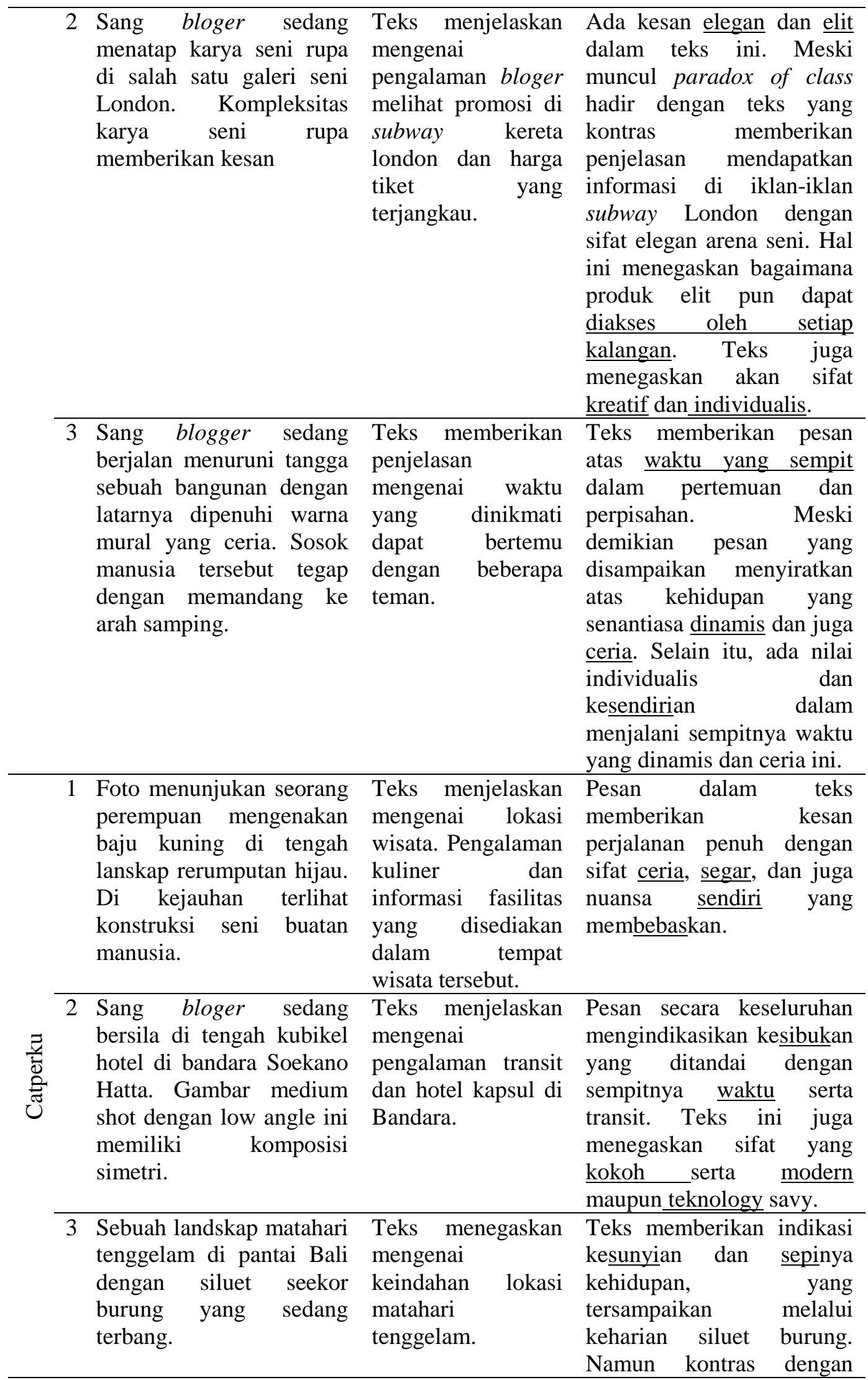


Dian Arymami: Diskoneksi Nomad: Paradoks Kemenjadian dalam Sosial Media bertema Travelling

keindahan dan keceriaan.
Dengan kata lain ada
kesunyian dan kesepian
yang ceria dan indah dalam
kehidupan.

Beberapa kata kunci dari representasi dan pemaknaan unggahan para travel blogers, dapat memberikan gambaran nilai serta identitas yang disampaikan melalui akun Instagram mereka. Hal ini dapat memberikan ilustrasi mengenai gaya hidup dan ideologi yang tersiarkan secara luas. Gaya hidup perjalanan yang digambarkan tidak lepas dari kelas elit, elegan dan budaya tinggi. Ada sifat yang melekat pada identitas keseluruhan yang menunjukan diri yang kreatif, eksploratif/aktif, positif, mandiri dan percaya diri. Individual yang terus menjadi dan kreatif juga ditekankan bagik secara visual maupun tekstual. Misalnya pesan atas individu yang terjebak dalam 'comfort zone' (zona nyaman) kehidupan disinggung sebagai kritikan yang tidak mencerminkan identitas yang positif. Dengan demikian, individu sebagai traveller merupakan sosok-sosok yang menerima dan mendukung perubahan, penuh dengan eksplorasi, dan mencari tantangan. Nilai individualisme ditegaskan melalui foto-foto kesendirian dan pesan-pesan tekstual yang mengacu pada kedirian; subject of grammar menegaskan hal ini.

Travel disisipkan sebagai aktifitas sentral kehidupan yang dikejar. Pekerjaan menjadi bagian yang mendukung aktifitas-aktifitas traveling yang dilakukan. Atau dengan kata lain pekerjaan diletakkan sebagai aktifitas yang semata untuk penghasilan, melelahkan, dan tidak menyenangkan. Aktifitas bekerja menjadi sekedar prasyarat untuk dapat membeli perjalanan sebagai aktifitas hidup yang utama. Foto pertama dari @kartupos dalam penelitian ini, misalnya menjelaskan pekerjaan berjalan sebagai travel blogger juga membutuhkan liburan. Pesan yang sama tersirat dalam unggahan-unggahan yang tidak menyinggung tentang pekerjaan sebagai bagian dari penghasilan hidup. Hal ini tampak pada gambaran akses tempat berwisata yang membutuhkan dana tidak sedikit. Rekreasi di galeri seni, tempat makan, hotel dan wilayah geografis di dataran Eropa dengan sendirinya menyiratkan kebutuhan finansial untuk mengakses aktifitas leisure demikian. Meski demikian, pesan yang disampaikan dalam berbagai unggahan travelling adalah aksesibilitas yang dimungkinkan buat individu mana pun yang menginginkannya.

Nilai-nilai mengenai perjalanan yang disiratkan sebagai bagian dari gaya hidup merupakan hal yang personal, menyenangkan, modern, mudah dan menenangkan. Meski demikian ideologi kapitalistik yang berpusat pada kepentingan pasar tidak lepas dari berbagai pesan gaya hidup terkini ini. Hal yang paling menonjol adalah unggahan di tempat rekreasi buatan manusia (gedung, bangunan, hotel, galeri, restauran, dstnya) cenderung lebih banyak daripada unggahan mengenai alam dan landskap yang dikunjungi. Fakta bahwa lebih banyak gambar tempat rekreasi dan bangunan kreasi manusia yang menjadi obyek ulasan perjalanan dan unggahan memperkuat keterjalinan dengan kepentingan industri tempat wisata dan ide kapitalistik dalam teks. Konteks komersialisasi dan 
publikasi tempat-tempat buatan manusia juga lebih banyak didukung dengan teks caption foto.

Eksplorasi perjalanan alam yang berada diluar wilayah wisata atau belum menjadi bagian dari industri pariwisata tidak terlalu banyak. Foto-foto yang menggambarkan alam cenderung menunjukan keindahan dan pesan tekstual sebagai pengantar foto alam cenderung bersifat motivasional atau pengalaman.

Kontras antara dua hal berupa tempat wisata buatan manusia dengan wisata alam pada sisi jumlah dan sifat pesan menegaskan gaya hidup traveling/perjalanan mewujud dalam leisure (waktu luang) yang bersifat rekreasi (aktifitas waktu luang) ketimbang leisure yang sepenuhnya berbentuk leisure. Hal ini merepresentasikan ide kapitalis untuk merasuk dalam aktifitas leisure masyarakat. Dengan kata lain, waktu luang digiring untuk dipergunakan dalam rekreasi yang memiliki nilai tukar finansial. Aktifitas rekreasi yang terjalin dalam industri berpusat pada ideologi kapitalis akan dengan sendirinya meletakan perjalanan berkelindan diatas dinamika kepentingan industri pariwisata tempat rekreasi.

Ide kapitalistik dalam gaya hidup perjalanan melekat dengan sosialisasi wacana kenikmatan waktu luang yang disampaikan oleh para travel bloggers. Pada dasarnya aktifitas travel bloggers menggunakan Instagram tidak lain menjadi bagian dari medium perpanjangan penjualan konten dan berjalin erat dengan industri budaya populer. Hal ini dapat dilihat dengan mudah melalui hyperlinks atau tautan menuju medium konten lain dalam membangun profesionalisme sebagai penulis perjalanan dan sekaligus dengan tersirat mempromosikan berbagai sponsor perjalanan mereka. Sebagai sebuah industri budaya dan secara spesifik terkandung dalam industri media hiburan dalam penjualan konten, interaktifitas atau enggangement dengan audiens tampak diperhatikan dalam konten travel bloggers. Hal ini disisipkan dalam caption tekstual yang mengiringi foto unggahan. Interaktifitas dengan audiens disusun dalam bentuk pertanyaan dan permintaan untuk komentar.

Merangkum pesan dalam unggahan travel bloggers menunjukan representasi atas kemandirian, kesendirian atau individualisme yang kuat, kreatifitas, elegan, bebas dan modern. Perjalanan sendiri dilihat sebagai kebutuhan primer yang menyenangkan, ceria dan menenangkan.

\section{Simpulan}

Hasil pembedahan unggahan travel blogger melalui akun Instagram menunjukan adanya representasi atas kemandirian, kesendirian atau individualisme yang kuat, kreatifitas, elegan, bebas dan modern. Sedangkan perjalanan sendiri dilihat sebagai kebutuhan primer yang menyenangkan, ceria dan menenangkan.

Fenomena travelling sebagai bagian dari gaya hidup masyarakat yang tersiar melalui media sosial menegaskan interkoneksi fenomena ini dengan dinamika budaya populer. Budaya populer yang identik dengan budaya massa berupaya menyeragamkan produk budaya sebagai "proyek penyeragaman selera dan cita rasa" (homogenization of state). Salah satu wujud kebudayaan yang 
Dian Arymami: Diskoneksi Nomad: Paradoks Kemenjadian dalam Sosial Media bertema Travelling

dihasilkan dengan adanya keterlibatan media massa adalah kebudayaan massa atau mass culture dan kebudayaan popular atau pop culture.

Generalisasi dari berbagai persamaan yang dapat ditemukan dalam obyek kajian menegaskan bagaimana kesatuan atas nilai perjalanan mengerucut pada sebuah gaya hidup yang seragam. Hal ini, sebagaimana dipaparkan memberikan penegasan atas nilai-nilai aktifitas perjalanan dan identitas individual yang "kekinian". Mengambil pendekatan mengenai subyektifitas, diri dan konsep Delueze dan Guattari dalam membaca fenomena traveling ini menawarkan sebuah kontradiksi atau konteks paradoksikal pada level ketidaksadaran manusia.

Mengkontekstualisasikan konsep molar dan molekular Deleuse dan Gauttari dalam hasil representasi travel bloggers, maka traveling atau berwisata yang telah menjadi gaya hidup masyarakat merupakan bagian dari industri masa yang tak lain bersifat kemenyatuan. Ada keseragaman atas pola dan nilai kehidupan yang diamini. Namun, lebih lanjut melihat representasi dari teks-teks travel bloggers, ada nilai yang dominan dan konstan pada semua teks dalam menyampaikan mengenai tentang kebebasan dan kesendirian. Aktifitas masal yang menjadi bagian dari molekuar ditegaskan dengan kesendirian dan personal yang terlepas dari kebersamaan ataupun penyatuan. Hal ini menunjukan konsep molar yang tegas hadir dalam aktfitas traveling tersebut. Ada paradoks yang hadir di sini dalam konteks massal dan personal yang menyatu sekaligus membelah. Sebuah gerakan molekular dan molar di saat yang sama.

Pada tataran ini, menggunakan kacamata Deleuze dan Gauttari, subyek skizo yang merupakan individual yang terus menjadi (personalitas yang senantiasa dinamis tanpa henti) merupakan bagian dari kelahiran masyarakat skizofrenik mewujud dalam fenomena traveling yang saat ini sedang populer di kalangan masyarakat. Individu yang terus menjadi ini hadir dalam sifat molekular dan molar yang terjalin dalam nilai-nilai aktifitas traveling, sebagaimana telah disampaikan paradoks dalam nilai kolektif sekaligus individual. Tak lain dari fenomena traveling yang sudah melekat dalam keseharian, membawa masyarakat untuk bersama-sama menjadi sendiri dan sekaligus sendiri bersama-sama. Ada kebersamaan yang intim dalam proses perjalanan yang sekaligus membawa diskoneksi dari kebersamaan yang diamini. Hasil ini lebih lanjut mengungkapkan fenomena diskoneksi, kesendirian dan kemandirian secara masal yang dapat ditelisik lebih lanjut dengan penelitian sosial untuk melihat pergembangan geseran interaksi sosial di tengah masyarakat melalui budaya berwisata.

\section{Ucapan Terima Kasih}

Hibah Penelitian Departemen Ilmu Komunikasi, UGM.

\section{Daftar Pustaka}

ASEANUP (March 2018, 20). Top 50 Blogs from Indonesia 2018. https://aseanup.com/top-50-blogs-indonesia/, diakses pada 2018, Maret 27 
Azariah, Ruth Deepti. (2017). Tourism, Travel, and Blogging: A discursive analysis of online travel narratives (New Directions in Tourism Analysis) 1st Edition. New York: Routledge.

Deleuze and Guattari. (1977). Anti-Oedipus: Capitalism and Schizophrenia. Viking Press.

Galani-Moutafi, Vasiliki. (2000). The Self and the Other: Traveler, Ethnographer, Tourist. Annals of Tourism Research. 27. 203-224. 10.1016/S01607383(99)00066-3.

Gani, Kemal. (2015). 8 Wajah Kelas Menengah. Jakarta: Gramedia Pustaka Utama

Hermawan, Heru. (2017). Traveling sebagai Gaya Hidup Mahasiswa Yogyakarta. Journal Sosiologi UNY 1:1.

Mansfield, Nick (2000). Subjectivity: Theories of the Self from Freud to Haraway. NYU Press

Marine-Roig, Estella. (2014). A webometric analysis of travel blogs and review hosting: the case of Catalonia. Journal of Travel \& Tourism Marketing 31 (3) 381-396.

Noth, Winfried. (1990). Handbook of Semiotics. Indiana University Press

Trinity. (2007). The Naked Traveler. Yogyakarta: C I publishing

Turkel, Shirley. (1995). Life on Screen: Identity in the Age of Internet. UK: Simon $\&$ Schuster

Turkel, Shirley. (2005). The Second Self: Computers and The Human Spirit. London: The MIT Press.

Utari, Marthapuri Dwi (24 Juli, 2018).11 Travel Blogger Terkenal Asal Indonesia yang Suka dengan Petualangan. Terarsip dalam https://highlight.id/daftarnama-travel-blogger-indonesia-sukses-terkenal/ diakses 10 September 2018

Yudasmoro. (2012). Travel Writer. Solo: Metagraf, Creative Imprint of Tiga Serangkai.

Yuwoshadi \& Gani. (2015). Delapan Wajah Kelas Menengah. Jakarta: Gramedia Pustaka Utama. 